\title{
A longitudinal study on illness perceptions in hemodialysis patients: changes over time
}

Alexandra Tasmoc ${ }^{1}$, Simona Hogas ${ }^{1,2}$, Adrian Covic ${ }^{1,2}$

1Dialysis and Renal Transplantation Center, "Dr.C.I. Parhon" University Hospital lasi, Romania

${ }^{2}$ Nephrology Department, "Gr. T. Popa" University of Medicine and Pharmacy, lasi, Romania

Submitted: 10 January 2013

Accepted: 20 February 2013

Arch Med Sci 2013; 9, 5: 831-836

DOI: 10.5114/aoms.2013.38678

Copyright @ 2013 Termedia \& Banach

\section{Abstract}

Introduction: Self-regulatory theory explains how patients' illness representations influence self-management behavior. The aim of this study was to examine the changes that occur in disease perceptions after 6 years in hemodialysis patients.

Material and methods: A total of 81 clinically stable patients (53.6\% males, meanage $54 \pm 12.54$ years, mean hemoglobin level $11 \pm 1.52 \mathrm{~g} / \mathrm{dl}$, mean Kt/V $1.49 \pm 0.21$ ) who were treated with hemodialysis three times weekly completed questionnaires on illness representations in 2005, and then at follow-up, in December 2011, 47 patients. IPQ-R (Illness Perceptions Questionnaire-Revised) was used to assess patients' illness perceptions.

Results: After a long period of years ( 6 years), patients had a stronger perception of a chronic course of the disease (timeline; $p<0.001$ ), considered hemodialysis more efficient in controlling end stage renal disease (ESRD) (treatment control; $p<0.05)$, considered that their disease had less serious consequences for their life (consequences; $p<0.05$ ), and also registered a less intense emotional response to their illness (emotional representation; $p<0.05$ ). Two of the seven components of illness representations (personal control, cyclical symptoms) remained unchanged. Treatment control perceptions were also predictive of mortality after controlling for covariates (age, gender, dialysis vintage, blood hemoglobin level and $\mathrm{Kt} / \mathrm{V})(\mathrm{HR}=0.13,95 \% \mathrm{Cl}: 0.02-0.75, p=0.022)$.

Conclusions: Our results show that patients' illness perceptions vary over a significantly long follow-up period, in the sense of having more optimistic views towards their illness perceptions.

Key words: end-stage renal disease, hemodialysis, illness perceptions, Illness Perceptions Questionnaire-Revised.

\section{Introduction}

Medical interventions have changed considerably over the last decade, in that many illnesses, once considered terminal, are now treated as chronic medical conditions. Chronic kidney disease (CKD) is one of the main problems of health care organization and the main cause of mortality worldwide [1].

End stage renal disease (ESRD) patients have a high burden of disease (particularly cardiovascular comorbidities) affecting their quality of life (QoL) and dramatically shortening life expectancy [2]. Stressors for indi-
Corresponding author: Prof. Adrian Covic MD, PhD, FRCP (London), FERA "Dr C I Parhon" Hospital Nephrology Clinic and the Dialysis and Transplantation Center B-dul Carol I, nr. 50 6000 lasi, Romania Phone: +40722280247 Fax: +40 232211752 E-mail: adrianccovic @gmail.com 
viduals on hemodialysis can be treatment-related such as dietary and fluid restrictions and a large pill burden, or psychosocial such as alterations in sexual functions, changes in self-confidence, and panic of death [3]. In a recent study, vacation limitation, fatigue, and uncertainty about the future were other real causes for worry in hemodialysis patients [4].

For the patient, the greatest impact of the disease lies in the effect it has on their ability to continue with a "normal" daily life and this will necessarily be their focus of interest. It is very important to understand how the perceptions, experience and impact of living with hemodialysis might influence a patient's interpretations and response to it.

The whole set of mental representations is described best by the self-regulatory theory, which represents a conscious, personal health management system that, broadly, considers that a patient will accept and self-implement medical advice only through self-regulation. The first approach was postulated by Kanfer: initially, the patient monitors his behavior and sees how his health is affected by a series of factors. If the results are wanted ones, he will continue the specific behavior; if the results are unwanted ones, he will change it [5]. The second approach, widely used, is Leventhal's theory: the patient needs to decide on a health-care active plan. Leventhal's Self-Regulation Theory postulates that patients construct their own representations or models which help them make sense of their experience, providing a basis for their coping responses [6].

Beliefs about illness or illness representations comprise multiple dimensions including [6]: identi-

Table I. Patients' characteristics and clinical outcome parameters $(n=47)$

\begin{tabular}{|lc|}
\hline Parameter & Value \\
\hline Age [years], mean \pm SD & $53.62 \pm 11.24$ \\
\hline Sex, female, $n(\%)$ & $29(61.7)$ \\
\hline Primary cause of renal failure, $n(\%)$ & $1(2.1)$ \\
\hline Lupus nephritis & $22(46.8)$ \\
\hline Glomerulonephritis & $7(14.9)$ \\
\hline ADPKD & $8(17.0)$ \\
\hline Chronic tubulo-interstitial & $9(19.2)$ \\
\hline Others & $13.38 \pm 3.77$ \\
\hline Years on dialysis, mean \pm SD & 6 \\
\hline Minimum years on dialysis & 23 \\
\hline Maximum years on dialysis & $11.60 \pm 2.07$ \\
\hline Hemoglobin [g/dl], mean \pm SD & $1.59 \pm 0.30$ \\
\hline Kt/V, mean \pm SD & $3.77 \pm 0.32$ \\
\hline Serum albumin [g/dl], mean \pm SD & $6.78 \pm 0.78$ \\
\hline Total protein [g/dl], mean \pm SD & \\
\hline
\end{tabular}

ty, cause, time line, consequences, and curability/controllability.

The main purpose of the present study was to examine, in a group of hemodialysis patients, for the first time in a long-term follow-up period (6 years) the dynamics of illness representations.

\section{Material and methods}

The hemodialysis patients who responded at the baseline $(n=81)$ were invited to participate in the present study (follow-up). So, the current study population consisted of 47 chronic hemodialysis patients ( $4 \mathrm{~h} /$ session, 3 times/week). Mean age was $53.62 \pm 11.24,29$ female $(61.7 \%)$. The values for hemoglobin $(\mathrm{g} / \mathrm{dl}), \mathrm{Kt} / \mathrm{V}$, albumin and total protein were recorded for each patient. The means are shown in Table I.

Of the whole sample, 34 patients did not participate in the study due to the following reasons: 21 died, 5 received renal transplant $(3$ males and 2 females), 2 changed dialysis modality, 2 moved to a different dialysis center, and 4 returned the questionnaire incomplete.

All patients were informed about the purpose of the study and gave their consent prior to participation. Consenting patients were handed the questionnaire IPQ-R.

The study was approved by the Hospital's Ethical Committee and was performed in agreement with the Helsinki declaration of human rights.

\section{Instruments}

The Illness Perception Questionnaire Revised (IPQ-R) was used to measure patients' cognitive and emotional representations of their illness. The instrument is a theoretically derived measure, designed to assess dimensions of illness perceptions (identity, time line, consequences, control and cause) across a range of illnesses [7, 8]. The instrument was revised to include measures of perceptions of duration of illness (time acute/chronic) and fluctuation in illness over time (time line cyclical); it also distinguishes perceptions of "treatment control" and "personal control" over illness. The revised version includes a new dimension "illness coherence" (how clear and comprehensive an individual feels his illness to be).

A new measure of "emotional representations" is also included [8]. The identity scale was not included in our analysis.

IPQ-R has been used with diverse patient populations suffering from conditions such as fibromyalgia [9], head and neck (HN) cancer [10], pulmonary disease [11], vestibular schwannoma [12], and women with breast cancer undergoing chemotherapy [13].

Subjects indicated their degree of agreement or disagreement on a 4-point scale ranging from "strongly disagree" to "strongly agree". 


\section{Statistical analysis}

The data were analyzed using SPSS version 17.0 for Windows. Values of $p<0.05$ were considered statistically significant. Paired samples $t$-tests were used to investigate whether patients' illness perceptions with its seven scales differed from baseline. Independent-samples $t$ test was used to compare means. Descriptive statistics of the demographic data of the study population were calculated. Cox proportional hazard models were used to examine the association between illness perceptions and survival.

\section{Results}

Descriptive data of patients are shown in Table I. Illness representation scores for the seven dimensions assessed at baseline and follow-up are presented in Table II. The evolution of the 6 dimensions of IPQ at baseline and follow-up are also presented in Figure 1.

Paired samples $t$ test showed that scores of two subscales of IPQ (personal control, cyclical symptoms) remained unchanged $(p>0.05)$. The average scores of the timeline, treatment control, and coherence subscales were higher at follow-up than at baseline.

There were significant differences between patients' scores in the timeline of disease subscale. At follow-up the average scores of the timeline of disease were higher than at baseline. At followup, patients were more convinced that their illness had a chronic course $(p<0.05)$.

We found significant differences between the patients' scores in the consequences of disease. At follow-up they registered lower scores, meaning that they did not perceive worse consequences of the disease upon their life $(p<0.05)$.

In terms of personal control of disease, there were no significant differences between the patients' scores at baseline and at follow-up. There was no change in how patients consider that disease can be influenced by their own actions ( $p>0.05$ ).

There were significant differences between patients' scores in the treatment control subscale

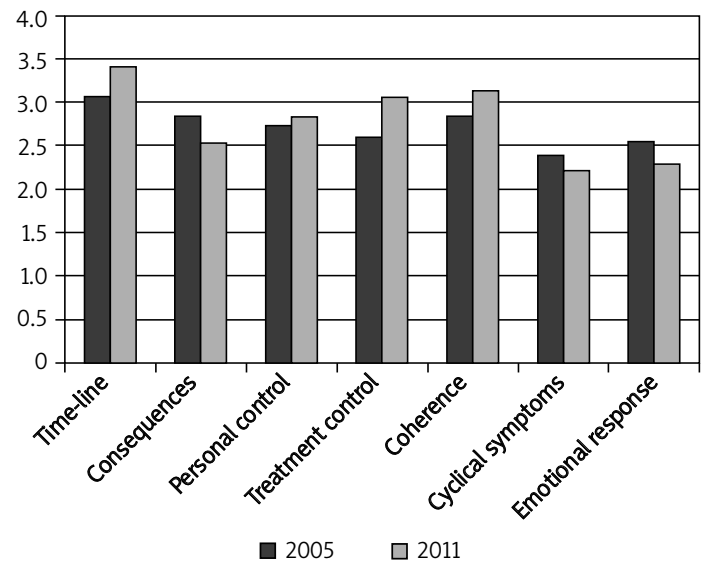

Figure 1. Evolution of the 6 dimensions of IPQ-R at baseline and follow-up

at baseline and follow-up, i.e. patients attributed more effectiveness of treatment at follow-up than at baseline $(p<0.05)$.

Also we found significant differences between patients' scores in the coherence of disease subscale, i.e. at follow-up they were able to understand and make sense of their disease quite well compared to baseline $(p<0.05)$.

In terms of cyclical symptoms, there were no significant differences between the patients' scores registered at baseline and at follow-up $(p>0.05)$, i.e. patients did not change their ability to make predictions on disease course and its complications.

There were significant differences between patients' scores in the emotional response subscale at baseline and follow-up; at follow-up patients registered a less intense emotional response to their illness $(p<0.05)$.

Also, we analyzed the influence of the variables age (group 1: $\geq 50$ years vs. group 2: < 50 years) and gender (male vs. female) among patients' illness perceptions subscales. In this report, the randomized study population was divided at age 50, which was close to its median age (54). The analysis was conducted with independent-samples $T$ test. There were no significant differences between the groups in patients' illness representations scales $(p>0.05)$ (Table III).

Table II. Comparison between illness representation dimensions - baseline vs. follow-up

\begin{tabular}{|c|c|c|c|}
\hline Measure & Baseline, mean \pm SD & Follow-up, mean \pm SD & Value of $p$ from paired $t$ test \\
\hline Time-line & $3.07 \pm 0.5$ & $3.41 \pm 0.5$ & $<0.001$ \\
\hline Consequences & $2.84 \pm 0.6$ & $2.54 \pm 0.6$ & 0.005 \\
\hline Personal control & $2.74 \pm 0.3$ & $2.83 \pm 0.3$ & 0.169 \\
\hline Treatment control & $2.60 \pm 0.3$ & $3.05 \pm 0.3$ & 0.001 \\
\hline Coherence & $2.84 \pm 0.4$ & $3.13 \pm 0.5$ & 0.007 \\
\hline Cyclical symptoms & $2.39 \pm 0.3$ & $2.22 \pm 0.5$ & 0.094 \\
\hline Emotional response & $2.55 \pm 0.6$ & $2.29 \pm 0.7$ & 0.036 \\
\hline
\end{tabular}


Table III. Mean scores of illness perception Questionnaire-Revised Scales in relation to demographic characteristics of patients on hemodialysis $(n=47)$

\begin{tabular}{|lccccccc|}
\hline IPQ Scales & \multicolumn{3}{c}{ Age [years] } & & & \multicolumn{3}{c|}{ Gender } \\
\cline { 2 - 7 } & $<50$ & $\geq 50$ & Value of $p$ & Male & Female & Value of $p$ \\
\hline Time line & $3.42 \pm 0.79$ & $3.40 \pm 0.52$ & 0.09 & $3.37 \pm 0.62$ & $3.44 \pm 0.40$ & 0.06 \\
\hline Consequences & $2.62 \pm 0.79$ & $2.49 \pm 0.60$ & 0.52 & $2.46 \pm 0.66$ & $2.59 \pm 0.68$ & 0.54 \\
\hline Personal control & $2.95 \pm 0.38$ & $2.76 \pm 0.35$ & 0.09 & $2.81 \pm 0.45$ & $2.85 \pm 0.32$ & 0.69 \\
\hline Treatment control & $3.05 \pm 0.39$ & $3.06 \pm 0.33$ & 0.95 & $3.06 \pm 0.33$ & $3.05 \pm 0.37$ & 0.91 \\
\hline Coherence & $3.26 \pm 0.62$ & $3.05 \pm 0.47$ & 0.19 & $3.16 \pm 0.46$ & $3.11 \pm 0.58$ & 0.77 \\
\hline Cyclical symptoms & $2.21 \pm 0.52$ & $2.22 \pm 0.59$ & 0.93 & $2.25 \pm 0.48$ & $2.20 \pm 0.60$ & 0.77 \\
\hline Emotional response & $2.32 \pm 0.88$ & $2.27 \pm 0.66$ & 0.85 & $2.12 \pm 0.60$ & $2.39 \pm 0.81$ & 0.23 \\
\hline
\end{tabular}

Table IV. Unadjusted and adjusted survival models evaluating illness perceptions as predictor of survival

\begin{tabular}{|lcc|}
\hline Illness perceptions & $\begin{array}{c}\text { Unadjusted } \\
\mathrm{HR}(95 \% \mathrm{Cl})\end{array}$ & $\begin{array}{c}\text { Adjusted } 1 \\
\mathrm{HR}(95 \% \mathrm{Cl})\end{array}$ \\
\hline Timeline & $0.99(0.47-2.11)$ & $1.87(0.81-4.35)$ \\
\hline Consequences & $1.17(0.55-2.50)$ & $2.52(0.93-6.80)$ \\
\hline Personal control & $0.44(0.14-1.38)$ & $0.93(0.28-3.10)$ \\
\hline Treatment control & $0.64(0.21-1.99)$ & $0.13(0.02-0.75)^{*}$ \\
\hline Coherence & $0.54(0.22-1.31)$ & $0.72(0.25-2.07)$ \\
\hline Cyclical symptoms & $1.55(0.43-5.54)$ & $0.75(0.14-4.06)$ \\
\hline Emotional response & $1.22(0.64-2.32)$ & $1.12(0.47-2.60)$ \\
\hline
\end{tabular}

${ }^{1}$ Adjusted for age, gender, dialysis vintage, blood hemoglobin levels and $K t / N ;{ }^{*} p<0.05$

Furthermore, illness perception dimensions were evaluated in terms of their association with survival using Cox regression. First, we entered individually each of the illness perception dimensions. In this unadjusted analysis, none of the illness perception dimensions (timeline, consequences, personal control, treatment control, coherence, cyclical symptoms and emotional responses) was associated with survival $(p>0.05)$ (Table IV).

After we adjusted each illness perception dimension for clinical and sociodemographic variables (age, sex, dialysis vintage, blood hemoglobin level and $\mathrm{Kt} / \mathrm{V}$ ) the results changed for one dimension of the IPQ-R. Treatment control was associated with mortality $(\mathrm{HR}=0.13,95 \% \mathrm{Cl}: 0.02-0.75, p=0.022)$ (Table IV).

\section{Discussion}

Leventhal's Self-Regulatory Model (SRM), which takes into account the emotional as well as the objective rational response to illness, currently seems to offer the best system for identifying the determinants of patients' self-care behavior. The SRM differs from previous health belief models as it takes into account patients' current and past experience [14].
The ESRD patients who undergo hemodialysis treatment spend a large number of hours weekly in the dialysis unit, so they start to consider dialysis as part of their lives. Consequently, these individuals diagnosed with such illnesses are encouraged to adapt over the long term, rather than choose to die. They have to face many uncertainties and they have to find a better way to cope with the impact of renal replacement therapy (RRT).

Each of these patients is moving through a grief process. According to Kubbler Ross (1969) [15] there are five stages to this process: denial ("This can't be happening to me!"), anger ("How dare God do this to me?"), bargaining ("Just let me live to see my son graduate"), depression ("I can't bear to face going through this, putting my family through this!"), and the last stage, acceptance ("I'm ready, I don't want to struggle anymore!").

This aim of this longitudinal study was to explore for the first time the evolution of patients' illness perceptions on maintenance hemodialysis.

We demonstrated that two dimension of IPQ-R (personal control, cyclical symptoms) remained unchanged. Also, we found that the average scores of the timeline, treatment control, and coherence subscales were higher at follow-up than at baseline. Emotional representations were significantly less intense at follow-up. This implies that at baseline, patients were more emotionally affected by their condition than at follow-up. Also, after controlling for covariates, including age, gender, dialysis vintage, blood hemoglobin level and Kt/V, perception of treatment control was a significant predictor of mortality.

The previous report of our study [16], the first of its kind in an ESRD population aiming to assess the patients' illness perception, showed that patients view their illness as having a chronic course (time line), understand the illness well and can influence their disease by their own actions (personal control). Negative consequences of the disease upon their lives and emotional responses have been considerable. Also, we investigated whether or not dif- 
ferences between the group with patients with a short treatment duration ( $<1$ year) and the group with longer treatment duration ( $>6$ years) among the patients' illness perceptions were significant. The results were not significant. Vintage on dialysis did not influence the patients' illness perception.

In a cross-sectional study, it was demonstrated that hemodialysis patients who perceived more symptoms (identity), more frequent cyclic illness, more consequences, higher emotional response and more causes of the illness had a greater risk of depression [17].

In terms of the relationship between treatment adherence and illness perceptions, Kim et al., in a study of 151 hemodialysis patients, revealed that illness perceptions were negatively correlated with adherence to diet; patients who reported stronger negative perceptions about their disease were more non-adherent with dietary restriction [18].

Timmers et al. [19] studied illness representations and quality of life in 133 dialysis patients (91 hemodialysis and 42 peritoneal dialysis (PD) patients). The PD patients experienced a higher level of personal control $(p<0.001)$ and had significantly higher scores in illness coherence compared with hemodialysis patients $(p<0.001)$. Perception of more symptoms, more consequences and lower personal control was associated with lower well-being.

Previous studies showed that only one IPQ-R dimension, treatment control, was associated with mortality in hemodialysis patients; the effect remained stable if it was adjusted for some clinical and socio-demographic variables [20, 21].

Despite all this accumulating evidence supporting a relevant and significant role for illness perceptions, currently there are no longitudinal observations in dialysis patients investigating how these perceptions might change over time.

In a non-renal population such studies exist and show significant changes. Our findings are consistent with those of Lowson investigating the illness perception in diabetes patients. Lawson et al. showed that emotional representations decrease within 2 years after the diagnosis, whereas illness coherence increases [22]. In a 6-year longitudinal study of patients with osteoarthritis, Bijsterbosch et al. found that whereas the dimensions chronic time line and illness coherence increased, patients reported a reduced perception of personal control over their illness and emotional reaction to their disease [23].

In a comparison of IPQ scores in vestibular schwannoma patients $(n=80)$ and head and neck cancer patients $(n=68)$, Vogel et al. found that vestibular schwannoma patients significantly thought of their illness as a more chronic problem and had a significantly greater sense of illness coherence, compared to patients with recently diagnosed HN cancer patients. Also, lower scores were registered for emotional representations and they expected their illness to have significantly fewer consequences for their lives compared with recently diagnosed $\mathrm{HN}$ cancer patients [12].

Van Wilgen et al. reported that patients with fibromyalgia perceived disease to be chronic with serious consequences and perceived little personal control and little treatment control [9].

Despite the great importance of these mental views, patients rarely bring them up in the discussion with the medical staff, mostly because they are ashamed to recognize their presence, believing, at the same time, that these aspects are not important in regard to their medical recovery or outcome.

No longitudinal data, with such a long period of follow-up (6 years), were reported by other researchers previously. Our study is one of the first investigations in ESRD regarding patients' illness perceptions. One of the main disadvantages of the current study was the high rate of subject attrition due to death.

This study has important limitations. First, the sample size of patients was small, which may limit the generalizability. Second, age of the included patients was much lower than the present population in dialysis, and also the high vintage on dialysis of the participants. Nevertheless, our data point to the major relevance of longitudinal changes in patients' perceptions in the current, modern management of ESRD.

In conclusion, we describe an improvement in illness perceptions in a European hemodialysis population. After 6 years on dialysis, patients have fewer negative emotional reactions, understand better their disease, consider dialysis more efficient in controlling their end stage renal disease, and also perceive their illness as having a chronic course. Treatment control dimension was associated with mortality.

\section{Acknowledgments}

The present study was partially supported by a "Grigore T. Popa" University of Medicine and Pharmacy lasi, Romania grant (1640/01.02.2013) and by grant IDEI-PCE 2011 (PN-II-ID-PCE-2011-3-0637).

\section{References}

1. Nasiree M. Determined of factors QoL in hemodialysis from interview patients and nursing [Persian]. Shakiba J 2004; 4: 6-7.

2. Covic A, Gusbeth-Tatomir P, Goldsmith DJ. The challenge of cardiovascular risk factors in end-stage renal disease. J Nephrol 2003; 16: 476-86.

3. Mahdavi Mazdeh M, Nozari B, Hatmi Zn, Zamyad M, Mahdavi A. The impact of gender and marital status on therapeutic outcomes of maintenance hemodialysis patients. Int J Nephrol Urol 2009; 1: 124-8. 
4. Cinar S, Barlas GU, Alpar SE. Stressors and coping strategies in hemodialysis patients. Pak J Med Sci 2009; 25: 447-52.

5. Kanfer R, Ackerman PL. A self-regulatory skills perspective to reducing cognitive interference. In: Cognitive interference: theories, methods and findings. The LEA series in personality and clinical psychology. Sarason IG, Pierce G, Sarason BR (eds.) Hillesdale, NY, England Lawrence Erlbaum Associates, Inc, 1996; 441.

6. Leventhal HL, Benyamini Y, Brownlee S, et al. Illness representation: theoretical foundations. In: Perceptions of health and illness. Petrie KJ, Weinmann JA (eds.) Harwood Academic, Amsterdam 1997; 19-45.

7. Weinman J, Petrie KJ, Moss-Morris R, Horne R. The Illness Perception Questionnaire: a new method for assessing illness perceptions. Psychol Health 1996; 11: 431-46.

8. Moss-Morris R, Weinman J, Petrie KJ, Horne R, Cameron LD, Buick D. The Revised Illness Perception Questionnaire (IPQ-R). Psychol Health 2002; 17: 1-16.

9. van Wilgen $C P$, van Ittersum MW, Kaptein AA, van Wijhe $M$. Illness perceptions in patients with fibromyalgia and their relationship to quality of life and catastrophizing. Arthritis Rheumatism 2008; 3618-26.

10. Scharloo M, Baatenburg de Jong RJ, Langeveld TP, van Velzen-Verkaik E, Doorn-op den Akker MM, Kaptein AA Quality of life and illness perceptions in patients with recently diagnosed head and neck cancer. Inc Head Neck 2005; 27: 857-63.

11. Fisher M, Scharloo M, Abbink J, et al. The dynamics of illness perceptions: testing assumptions of Leventhal's common-sense model in a pulmonary rehabilitation setting. Br J Health Psychol 2010; 15: 887-903.

12. Vogel JJ, Godefroy WP, von der Mey A GL, le Cessie S Kaptein AA. Illness perceptions, coping and quality of life in vestibular schwannoma patients at diagnosis. Otol Neurotol 2008; 29: 839-45.

13. Shabahang H, Panahi G, Noferesti G, Sahebghalam H, Robubiat S, Bolurian M. Illness perception of breast cancer in affected women undergoing chemotherapy. Medical Journal of Islamic Republic of Iran 2011; 25: 76-81.

14. Harvey JN, Lawson VL. The importance of health belief models in determing self-care behaviour in diabetes. Diabet Med 2009; 26: 5-13.

15. Kübler-Ross E. On death and dying. Macmillan, New York 1969.

16. Covic A, Seica A, Gusbeth-Tatomir P, Gavrilovici O, Goldsmith DJA. Illness representations and quality of life scores in hemodialysis patients. Nephrol Dial Transplant 2004; 19: 2078-83.

17. Ibrahim N, Kong Chiew-Tong N, Desa A. Illness perception and health-related quality of life among hemodialysis patients. Pertanika J Soc Sci Hum 2011; 19: 173-81.

18. Kim Y, Evangelista LS. Relationship between illness perceptions, treatment adherence, and clinical outcomes in patients on maintenance hemodialysis. Nurs J 2010; 37: 271-81.

19. Timmers L, Thong M, Dekker FW, et al. Illness perceptions in dialysis patients and their association with quality of life. Psychol Health 2008; 23: 679-90.

20. Chilcot J, Wellsted D, Farrington K. Illness perceptions predict survival in haemodialysis patients. Am J Nephrol 2011; 33: 358-63.

21. van Dijk S, Scharloo M, Kaptein AA, et al.; NECOSAD Study Grup. Patients' representations of their end-stage renal disease: relation with mortality. Nephrol Dial Transplant 2009; 24: 3183-5.
22. Lawson VL, Bundy C, Harvey JN. The development of personal models of diabetes in the first 2 years after diagnosis: a prospective longitudinal study. Diabet Med 2008; 25: 482-90.

23. Bijsterbosch J, Scharloo M, Visser AW, et al. Illness perceptions in patients with osteoarthritis: change over time and association with disability. Arthritis Rheum 2009; 61: 1054-61. 